УДК 615.322:582.684.1

\title{
КОЛИЧЕСТВЕННОЕ ОПРЕДЕЛЕНИЕ ПРОИЗВОДНЫХ ГИПЕРФОРИНА В ТРАВЕ ЗВЕРОБОЯ ПРОДЫРЯВЛЕННОГО
}

\author{
() Р.ШІ. Хазиев", Л.И. Насыбуллина, А.С. Макарова, Л.Т. Мусина \\ Казанский государственный медицинский университет, ул. Бутлерова, 49, \\ Казань, 420012 (Россия), e-mail: xaziev@inbox.ru
}

Разработан способ определения производных гиперфорина в траве зверобоя продырявленного спектрофотометрическим методом. Относительная ошибка определения не превышает 1,5\%. Показано, что в траве зверобоя пятнистого (другом разрешенном для использования виде зверобоя) производные гиперфорина практически отсутствуют, что обусловливает его более низкую антимикробную активность в сравнении со зверобоем продырявленным. Производные гиперфорина локализованы преимущественно в цветках зверобоя продырявленного.

Ключевые слова: зверобои продырявленный и пятнистый, гиперфорин, стандартизация, антибактериальная активность.

\section{Введение}

В медицинской практике Российской Федерации применяются два вида рода зверобой (Hypericum L.): зверобой продырявленный (Hypericum perforatum L.) и зверобой пятнистый (четырехгранный) (Hypericum maculatum Crantz., синоним Hypericum quadrangulum L.) семейства Hypericaceae (Guttiferae). В настоящее время трава обоих видов зверобоя используется совершенно равноценно для приготовления настоев, производства настойки зверобоя, комплексных отечественных препаратов «Простанорм» и «Фарингал», а также является составной частью ряда бальзамов и эликсиров («Панта-Форте», «Эвалар», «Виватон», «Алтайский», «Демидовский»). Сухой экстракт из травы зверобоя продырявленного входит в состав препарата «Сибектан». Кроме того, на российском рынке присутствует ряд препаратов антидепрессантного действия на основе травы зверобоя продырявленного зарубежных производителей - «Гелариум Гиперикум», «Деприм», «Негрустин». Надо сказать, что до выхода в свет Государственной фармакопеи СССР XI издания, узаконившей равноценное использование обоих видов зверобоя [1, с. 323-325], зверобой пятнистый рассматривался как примесь к зверобою продырявленному и заготовкам не подлежал [2, с. 346-347]. В европейской фармакопее официален только один вид зверобоя - зверобой продырявленный [3].

Действующие вещества травы зверобоя представлены несколькими группами природных соединений, среди которых выделяются флавоноиды, антраценпроизводные, а также гиперфорин и его производные. Государственная фармакопея СССР ХІ издания предусматривает стандартизацию травы зверобоя по содержанию суммы флавоноидов [1, с. 323-325], Европейская фармакопея стандартизует траву зверобоя

Хазиев Рамиль Шамилевич - доцент кафедры фармакологии фармацевтического факультета с курсами фармакогнозии и ботаники, кандидат биологических наук, e-mail: xaziev@inbox.ru Насыбуллина Ляйсан Ильдаровна - студентка Макарова Алёна Сергеевна - студентка, e-mail: anela_90@mail.ru Мусина Линара Табрисовна - профессор кафедры микробиологии, доктор медицинских наук, e-mail: musina@kgmu.kcn.ru продырявленного по содержанию суммы производных антрацена («total hypericins») [3]. По содержанию гиперфорина (обладающего антибактериальной активностью [4], кроме этого, ряд исследователей считает, что гиперфорин и его производные ответственны за антидепрессантные эффекты препаратов зверобоя) стандартизуются только некоторые коммерческие экстракты зверобоя, предназначенные для производства биологически активных добавок.

\footnotetext{
* Автор, с которым следует вести переписку.
} 
С другой стороны, производные гиперфорина описаны только для одного из используемых видов - зверобоя продырявленного, который, вероятно, и должен использоваться для получения препаратов антимикробного действия и в этом случае стандартизоваться по содержанию данной группы соединений.

Цель нашей работы - сравнительное изучение содержания производных гиперфорина в двух фармакопейных видах зверобоя и разработка доступного метода их количественного определения.

\section{Экспериментальная часть}

В качестве объекта исследования использовали траву зверобоя продырявленного (Hypericum perforatum L.) и зверобоя пятнистого (Hypericum maculatum Crantz.), заготовленную в июне - июле 2011 года в различных районах Татарстана.

Запись УФ-спектров и определение оптических плотностей полученных растворов проводили на спектрофотометре LAMBDA 25 (Perkin Elmer, США) в кювете с толщиной слоя 10 мм.

Для тонкослойной хроматографии использовали пластины «Сорбфил» (ПТСХ-АФ-В, производитель ЗАО «Сорбполимер»). Извлечения хроматографировали в системе гексан - этилацетат (9 : 1), детектирование зон гиперфорина и его производных проводили в УФ-свете при 360 нм.

Оценку антибактериальной активности проводили методом двукратных серийных разведений на мясо-пептонном бульоне (МПБ) при рН 7,0 с тест-микробом Staphylococcus aureus ATCC 6538-P [5]. Однако метод серийных разведений в МПБ зачастую не позволяет визуально определить наличие или отсутствие роста из-за помутнения среды.

Чтобы устранить этот недостаток фармакопейной методики, нами был разработан метод, где антибактериальную активность определяли, делая пересев из каждой пробирки на чашки с мясо-пептонным агаром (МПА), которые затем инкубировали в термостате в течение 18-24 ч. Отмечали рост микроорганизмов. Разведение препарата, на котором отсутствовал рост тест-штамма, характеризовало антибактериальную активность препарата.

\section{Результаты и обсуждение}

Для качественного обнаружения гиперфорина использовали тонкослойную хроматографию на силикагеле («Сорбфил») в системе гексан - этилацетат $9: 1$ [6]. На пластинку наносили гексановые извлечения из травы двух видов зверобоя. Гиперфорин обнаруживали по интенсивной сине-фиолетовой флюоресценции в УФ-свете при 360 нм. Гиперфорин был обнаружен только в извлечении из травы H. perforatum (рис. 1).

Для дополнительного подтверждения наличия гиперфорина в извлечении из $H$. perforatum и отсутствия его в H. maculatum нами были записаны УФ-спектры обоих гексановых экстрактов. Известно, что гиперфорин имеет четко выраженную полосу поглощения при длине волны 278 нм [7]. Полученные УФспектры стали еще одним подтверждением того, что H. perforatum u H. maculatum различаются по содержанию гиперфорина (рис. 2). УФ-спектр извлечения из H. perforatum имел четко выраженный максимум при $278 \pm 3$ нм, тогда как у H. maculatum он практически отсутствовал.

Для установления корреляции между наличием гиперфорина и уровнем антимикробной активности травы зверобоя были проведены микробиологические испытания методом двукратных серийных разведений на МПБ (рН 7,0) и последующим пересевом методом репликаций на чашки Петри с МПА с тестмикробом Staphylococcus aureus ATCC 6538-Р. Для этого гексан из полученных извлечений отгонялся досуха под вакуумом, остаток растворялся в 20 мл 95\%-го этанола. Полученный раствор подвергался микробиологическим испытаниям (табл. 1).

Антибактериальная активность зверобоя продырявленного была в 4 раза выше зверобоя пятнистого. Таким образом, была подтверждена неравнозначность этих видов сырья в плане антимикробной активности и корреляция ее с содержанием гиперфорина.

Таблица 1. Антибактериальная активность извлечений из травы H. perforatum и H. maculatum (на культуре Staphylococcus aureus ATTC 6538-P)

\begin{tabular}{c|c}
\hline $\begin{array}{c}\text { Спиртовой экстракт }(1: 20), \\
\text { полученный после удаления гексана }\end{array}$ & $\begin{array}{c}\text { Максимальное разбавление извлечения, } \\
\text { инактивирующее размножение стафилококков }\end{array}$ \\
\hline H. perforatum & $1: 512$ \\
H. maculatum & $1: 128$ \\
\hline
\end{tabular}


Следующим этапом нашей работы стала разработка метода количественного определения суммы производных гиперфорина в траве зверобоя продырявленного. В зарубежной литературе описаны способы количественного определения гиперфорина в зверобое продырявленном методом ВЭЖХ со спектрофотометрической детекцией при 278 нм. Однако применение этого метода осложняется как его собственной дороговизной, так и высокой стоимостью гиперфорина как стандартного образца - соединения очень нестойкого и чувствительного к действию света и температуры.

Нами был выбран спектрофотометрический метод, основанный на избирательной экстракции гиперфорина и его производных гексаном, измерении оптической плотности полученного раствора при 278 нм и использовании для расчетов молярного показателя поглощения гиперфорина при этой длине волны. Были определены условия исчерпывающей экстракции гиперфорина и его производных по соотношению сырья и экстрагента и продолжительности нагревания (табл. 2).

Полученные результаты показали, что условиями исчерпывающей экстракции производных гиперфорина из травы зверобоя продырявленного является 30-минутная экстракция кипящим гексаном при соотношении сырья и растворителя $1: 100$.

Таким образом, все вышеизложенное позволило нам предложить следующую методику количественного определения.

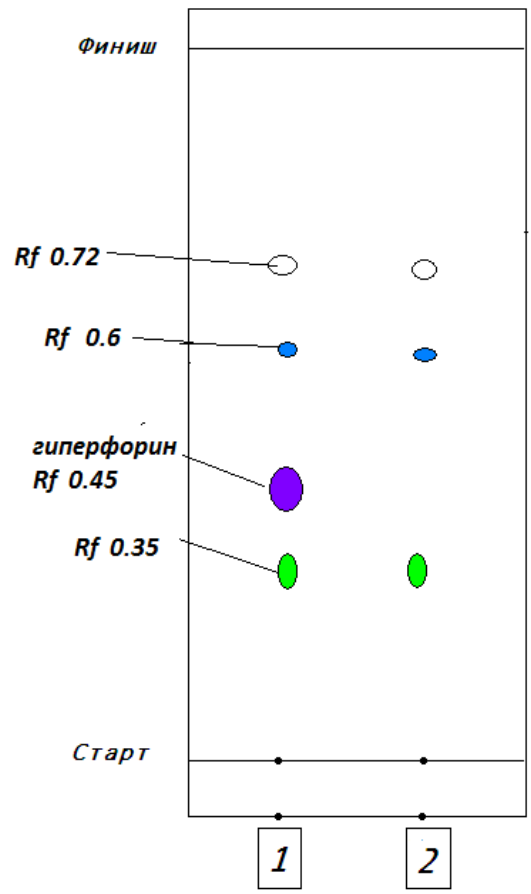

Рис. 1. ТСХ гексановых извлечений из травы $H$. perforatum (1) и H. maculatum (2) извлечений из травы

H. perforatum $и$ H. maculatum
Рис. 2. УФ-спектры гексановых

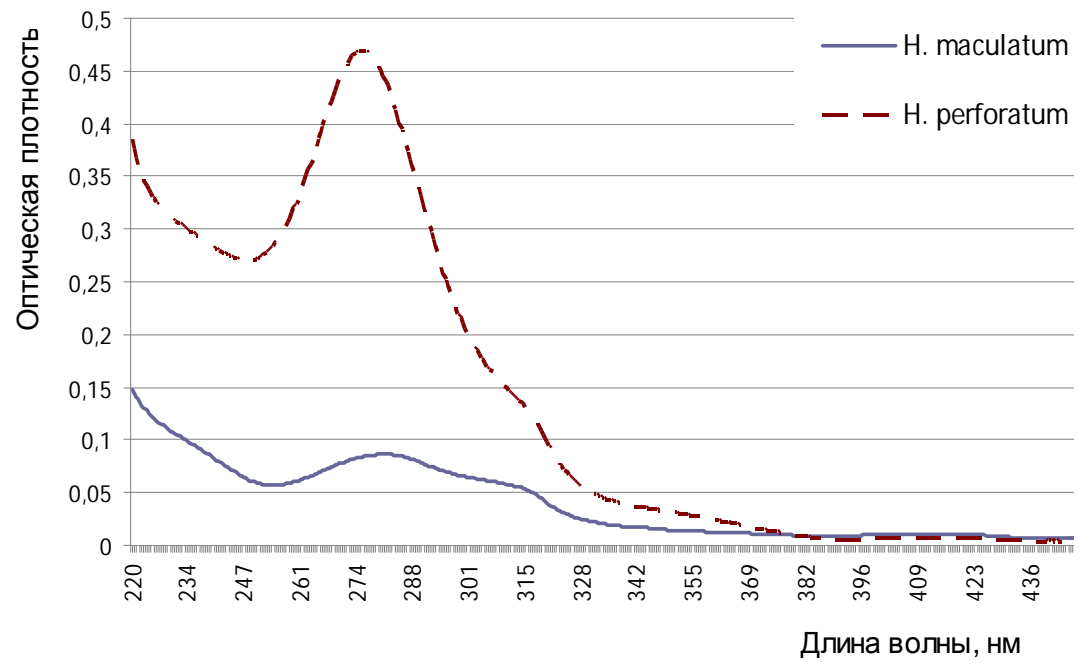

Таблица 2. Зависимость выхода гиперфорина и его производных из травы H. perforatum в гексан от параметров экстракции

\begin{tabular}{c|c|c}
\hline $\begin{array}{c}\text { Соотношение сырье (г) - } \\
\text { экстргент (мл) }\end{array}$ & Время экстракции, мин & $\begin{array}{c}\text { Содержание суммы производных гипер- } \\
\text { форина в пересчете на гиперфорин, \% }\end{array}$ \\
\hline $1: 100$ & 30 (при комнатной температуре) & $1,0 \pm 0,0$ \\
$1: 100$ & 60 (при комнатной температуре) & $1,1 \pm 0,0$ \\
$1: 100$ & 30 (при кипячении) & $1,3 \pm 0,0$ \\
$1: 100$ & 60 (при кипячении) & $1,3 \pm 0,1$ \\
$1: 100$ & 90 (при кипячении) & $1,3 \pm 0,0$ \\
$1: 200$ & 30 (при кипячении) & $1,3 \pm 0,0$ \\
$1: 200$ & 60 (при кипячении) & $1,3 \pm 0,0$ \\
\hline
\end{tabular}


Методика количественного определения суммы производных гиперфорина в траве зверобоя продырявленного. Аналитическую пробу сырья измельчают до размера 1 мм. Около 1 г сырья (точная навеска) помещают в колбу со шлифом вместимостью 250 мл, прибавляют 100 мл гексана. Колбу присоединяют к обратному холодильнику и нагревают на водяной бане при умеренном кипении гексана в течение 30 мин. Затем колбу охлаждают и фильтруют через бумажный фильтр в мерную колбу вместимостью 100 мл, доводя объем раствора до метки гексаном.

5 мл полученного извлечения переносят в мерную колбу вместимостью 25 мл и доводят объем раствора до метки гексаном. Измерение оптической плотности раствора проводят при длине волны 278 нм, используя в качестве раствора сравнения гексан. Содержание суммы производных гиперфорина в пересчете на гиперфорин и абсолютно сухое сырье в процентах $(\mathrm{X})$ вычисляют по формуле:

$$
X=\frac{D \cdot 536 \cdot 0,0006 \cdot 100 \cdot 100 \cdot 100 \cdot 25}{8200 \cdot m \cdot 5 \cdot(100-W)},
$$

где D - оптическая плотность испытуемого раствора; 536 - молекулярный вес гиперфорина; 8200 - показатель поглощения $6 \cdot 10^{-4}$ М раствора гиперфорина при 278 нм [7]; m - масса сырья в граммах; W - потеря в массе при высушивании, \%.

Для определения метрологических характеристик разработанной методики провели 10 параллельных определений (табл. 3).

Полученные результаты свидетельствуют об удовлетворительной воспроизводимости методики, ошибка единичного определения не превышает $\pm 1,5 \%$.

С помощью разработанной методики мы изучили распределение производных гиперфорина в различных частях зверобоя продырявленного (табл. 4).

Производные гиперфорина накапливаются преимущественно в цветках зверобоя продырявленного.

Таблица 3. Метрологические характеристики метода определения производных гиперфорина в траве $H$. perforatum

\begin{tabular}{c|c|c|c|c|c|c|cc}
\hline $\mathrm{f}$ & $\bar{X}$ & $\mathrm{~S}^{2}$ & $\mathrm{~S}$ & $\mathrm{P}$ & $\mathrm{t}(0,95 ; 9)$ & $\Delta \mathrm{x}$ & $\varepsilon, \%$ \\
\hline 9 & 1,3 & 0,0008 & 0,0281 & 0,95 & 2,26 & 0,0 & 1,5 \\
\hline
\end{tabular}

Таблица 4. Содержание производных гиперфорина в различных органах H. perforatum

\begin{tabular}{c|c|c}
\hline Трава & Листья & Цветки \\
\hline $1,3 \pm 0,0$ & $1,3 \pm 0,1$ & $2,8 \pm 0,2$ \\
\hline
\end{tabular}

\section{Bblводы}

1. Гиперфорин накапливается только в одном из фармакопейных видов зверобоя - зверобое продырявленном и локализован преимущественно в цветках растения.

2. Антибактериальная активность зверобоя продырявленного в отношении культуры золотистого стафилококка в 4 раза выше таковой у зверобоя пятнистого и может быть обусловлена различием в уровнях содержания производных гиперфорина.

3. Разработанный способ количественного определения производных гиперфорина в траве зверобоя продырявленного отличается хорошей воспроизводимостью, ошибка не превышает 1,5\%.

4. Трава зверобоя, предназначенная для получения препаратов антимикробного действия, должна стандартизоваться по содержанию производных гиперфорина.

\section{Список литературы}

1. Государственная фармакопея СССР: Вып. 2. Общие методы анализа. Лекарственное растительное сырье. 11-е изд., доп. М., 1989. 400 с.

2. Государственная Фармакопея СССР. 10-е изд., М., 1968. 1080 с.

3. European Pharmacopoeia. 5th ed. Sup. 5.6. Strasbourg, 2005.

4. Гуревич А.И., Добрынин М.Н., Колосов С.А., Поправко И.Д., Айзенман В.Е., Гарагуля А.Д. Гиперфорин антибиотик из Нурericum perforatum L. // Антибиотики. 1971. №16. C. 510-513. 
5. С 42-1348-91. Раствор хлорофиллипта спиртовый 1\%. Фармакопейный государственный комитет. Введ. 10.10.91. M., 1991. 4 c.

6. Adam P., Arigoni D., Bacher A., Eisenreich W. Biosynthesis of Hyperforin Hypericum perforatum // J. Med. Chem. 2002. Vol. 45. Pp. 4786-4793.

7. Быстров, Н.С., Добрынин В.Н., Колосов М.Н., Чернов Б.К. Химия гиперфорина. VI. Общая химическая характеристика // Биоорганическая химия. 1978. Т. 4, №6. С. 791-797.

Поступило в редакияию 31 июля 2012 г.

Khaziev R.Sh.", Nasybullina L.I., Makarova A.S., Musina L.T. QUANTITATIVE DETERMINATION OF HYPERFORIN DERIVATIVES IN THE HERB OF HYPERICUM PERFORATUM

Kazan State Medical University, Butlerova st., 49, Kazan, 420012 (Russia),e-mail:xaziev@inbox.ru

The way of determination of spectrophotometric method of hyperforin derivatives in the herb of Hypericum perforatum was developed. The relative error of determination doesn't exceed 1,5\%. It is shown that hyperforin derivatives are practically absent in the herb of Hypericum maculatum (this is different kind of Hypericum allowed for use), which causes its lower antimicrobial activity in comparison with Hypericum perforatum. Hyperforin derivatives are localized predominatly in the flowers of Hypericum perforatum.

Keywords: Hypericum perforatum and Hypericum maculatum, hyperforin, standardization, antibacterial activity.

\section{References}

1. Gosudarstvennaia farmakopeia SSSR: Vyp. 2. Obshchie metody analiza. Lekarstvennoe rastitel'noe syr'e. 11-e izd. [, Vol. 2. Common methods of analysis. Herbal drugs. 11th ed.]. Moscow, 1989. 400 p. (in Russ.).

2. Gosudarstvennaia farmakopeia SSSR. 10-e izd. [State Pharmacopoeia of the USSR. 10th ed.]. Moscow, 1968, 1080 p. (in Russ.). (in Russ.).

3. European Pharmacopoeia. 5th ed. Sup. 5.6. Strasbourg, 2005.

4. Gurevich A.I., Dobrynin M.N., Kolosov S.A., Popravko I.D., Aizenman V.E., Garagulia A.D. Antibiotiki, 1971, no. 16, pp. 510-513. (in Russ.).

5. FS 42-1348-91. Rastvor khlorofillipta spirtovyi 1\%. [Pharmacopoeial article 42-1348-91. Hlorofillipta alcohol solution of 1\%]. Moscow, 1991, 4 p. (in Russ.).

6. Adam P., Arigoni D., Bacher A., Eisenreich W. J. Med. Chem., 2002, vol. 45, pp. 4786-4793.

7. Bystrov, N.S., Dobrynin V.N., Kolosov M.N., Chernov B.K. Bioorganicheskaia khimiia, 1978, vol. 4, no. 6, pp. 791-797. (in Russ.).

\footnotetext{
* Corresponding author.
} 
